УДК 661.183.1:633(58+511): 677.544: 669.48

\title{
СУЛЬФОКАТИОНИТЫ НА ОСНОВЕ РАСТИТЕЛЬНОГО СЫРЬЯ И ГЛИЦИДИЛМЕТАКРИЛАТА
}

\author{
() Е.Е. Ергожин, А.И. Никитина, Г.К. Кабулова", Н.А. Бектенов \\ Институт химических наук им. А.Б. Бектурова, ул. Ш. Уалиханова, 106, \\ Алматы, 050010 (Казахстан), e-mail:kabgul@mail.ru
}

\begin{abstract}
Изучена возможность получения сульфокатионитов на основе растительного сырья (хлопка, пшеничной соломы, камыша) и глицидилметакрилата. Найдены оптимальные условия синтеза и исследованы их физико-химические свойства. В статических условиях изучена сорбция ионов тяжелых металлов $\mathrm{Cu}^{2+}, \mathrm{Zn}^{2+}, \mathrm{Ni}^{2+}, \mathrm{Co}^{2+}$ и $\mathrm{Pb}^{2+}$ новыми целлюлозосодержащими сорбентами из модельных сульфатных растворов в сравнении с промышленным сульфокатионитом КУ-2х8.

Ключевые слова: растительное сырье, глицидилметакрилат, сульфокатиониты, сорбционные свойства, ионы тяжелых металлов.
\end{abstract}

\section{Введение}

Сорбционный и ионообменный методы очистки сточных вод имеют большое значение для решения экологических задач $[1,2]$. В связи с этим проблема получения дешевых сорбентов с комплексом улучшенных физико-химических и эксплуатационных характеристик остается актуальной. Перспективность использования растительного сырья для синтеза ионитов обусловлена не только его доступностью, возобновляемостью и практически неисчерпаемостью, но и тем, что целлюлоза и лигнин, входящие в его состав, являются основой капиллярно-пористой структуры материалов. Адсорбционные свойства фитосорбентов на их основе определяются как наличием определенных функциональных групп, так и пористой структурой этих составляющих. Для получения ионитов использовали доступное растительное сырье хлопок, камыш и пшеничную солому, которая является отходом сельскохозяйственного производства. Хлопок на 98-99\% состоит из целлюлозы [3], основными компонентами пшеничной соломы являются целлюлоза (37\%), гемицеллюлозы (25\%) и лигнин (17\%) [4], эти же компоненты содержатся и в камыше (48\% полисахаридов). За счет химического модифицирования этих гидроксилсодержащих соединений можно синтезировать различные целлюлозосодержащие ионообменники.

Ергожин Едил Ергожаевич - генеральный директор, заведующий лабораторией ионообменных смол и мембран, доктор химических наук, профессор, академик НАН РК, тел.: (727) 291-30-74

Никитина Анна Ивановна - старший научный сотрудник лаборатории ионообменных смол и мембран, кандидат химических наук, тел.: (727) 291-30-52

Кабулова Гулжсиян Кахармановна - старший научный сотрудник лаборатории ионообменных смол и мембран, кандидат химических наук, тел.: (777) 668-02-88, e-mail: kabgul@ mail.ru Бектенов Несипхан Абжапарович - главный научный сотрудник лаборатории ионообменных смол и мембран, доктор химических наук, профессор, тел.: (727) 291-53-92, e-mail: bekten_1954@ mail.ru

\footnotetext{
* Автор, с которым следует вести переписку.
}

\section{Экспериментальная часть}

Сульфокатиониты на основе лигноцеллюлозного сырья получали в две стадии. Сначала хлопок $(\mathrm{X})$, пшеничную солому (С) или камыш (К) без предварительной активации сульфировали концентрированной 98\%-ной серной кислотой при комнатной температуре в течение 1 ч при массовом соотношении растительное сырье : $\mathrm{H}_{2} \mathrm{SO}_{4}$, равном 1 : 9. Затем, варьируя соотношение реагентов, температуру и продолжительность процесса, проводили химическое модифицирование сульфированного продукта глици- 
дилметакрилатом (ГМА), в результате чего были синтезированы иониты сетчатого строения КС-ГМА-Х, КС-ГМА-С, КС-ГМА-К. Синтез сульфокатионитов проводили в трехгорлой колбе, снабженной механической мешалкой, термометром и капельной воронкой. В реакционный сосуд загружали сульфированное растительное сырье и, перемешивая при нагревании, прикапывали ГМА, доводя температуру до $80^{\circ} \mathrm{C}$. После образования геля смесь выгружали в фарфоровые чашки и доотверждали в течение 6-15 ч при $70-140{ }^{\circ} \mathrm{C}$. Остывшую реакционную массу дробили и рассеивали, отбирая фракции с размером гранул 0,25-1,00 мм, отмывали 5\%-ным раствором едкого натра и переводили в $\mathrm{H}^{+}$-форму 5\%-ным раствором соляной кислоты, после чего сушили до постоянного веса под вакуумом при $25-30{ }^{\circ} \mathrm{C}$.

ИК-спектры катионитов снимали на спектрометре марки NICOLET 5700 FT-IR в области 400-4000 $\mathrm{cm}^{-1}$ в таблетках с $\mathrm{KBr}$ (200 мг $\mathrm{KBr}$ и 1 мг вещества). Топологию поверхностей катионитов исследовали методом сканирующей электронной микроскопии на приборе JSM-6510LA фирмы JEOL (Япония).

Термостойкость сульфокатионитов изучали методом термогравиметрического анализа (ТГА) на приборе «Mettler Toledo» (Швейцария) на воздухе в интервале температур $20-500{ }^{\circ} \mathrm{C}$ со скоростью нагрева $15{ }^{\circ} \mathrm{C} /$ мин. Термический гидролиз проводили при кипячении в воде навесок катионитов в колбах с обратным холодильником в течение 50 ч.

Катиониты КС-ГМА-Х, КС-ГМА-С и КС-ГМА-К использовали для сорбции в $\mathrm{H}^{+}$-форме. Для сравнения сорбционных свойств полученных катионообменников была исследована извлекающая способность и промышленного сильнокислотного сульфокатионита со средней степенью сшивки КУ-2х8. Извлечение ионов $\mathrm{Cu}^{2+}, \mathrm{Zn}^{2+}, \mathrm{Ni}^{2+}, \mathrm{Co}^{2+}$ и $\mathrm{Pb}^{2+}$ из модельных растворов, содержащих $\mathrm{CuSO}_{4}, \mathrm{ZnSO}_{4}, \mathrm{NiSO}_{4}, \mathrm{CoSO}_{4}$ и $\mathrm{Pb}\left(\mathrm{NO}_{3}\right)_{2}$ марок «х.ч.», изучали при периодическом перемешивании в статических условиях при соотношении катионит : раствор, равном $1: 400$, и комнатной температуре $22 \pm 2{ }^{\circ} \mathrm{C}$. Продолжительность контакта составляла от 1 ч до 7 сут. Сорбционную емкость (CE) рассчитывали по разности исходной и равновесной концентрации растворов, которую определяли с помощью классической полярографии на фоне $0,5 \mathrm{M}$ $\mathrm{NH}_{4} \mathrm{CI}$ по волнам восстановления $\mathrm{Cu}^{2+}\left(E_{1 / 2}=-0,16 \mathrm{~B}\right), \mathrm{Zn}^{2+}\left(E_{1 / 2}=-1,02 \mathrm{~B}\right), \mathrm{Ni}^{2+}\left(E_{1 / 2}=-1,12 \mathrm{~B}\right), \mathrm{Co}^{2+}$ $\left(E_{1 / 2}=-1,36 \mathrm{~B}\right)$ и $\mathrm{Pb}^{2+}\left(\mathrm{E}_{1 / 2}=-0,41 \mathrm{~B}\right)$. Полярограммы снимали на полярографе ПУ-1 в термостатированной ячейке при $25 \pm 0,5^{\circ} \mathrm{C}$, используя в качестве электрода сравнения насыщенный каломельный электрод.

\section{Обсуждение результатов}

Оптимальные условия сульфокатионитов на основе растительного сырья и ГМА и некоторые их физико-химические свойства приведены в таблице 1.

Как следует из таблицы 1 , полученные сульфокатиониты обладают высокой статической обменной емкостью (СОЕ), значения которой выше, чем у активных сульфоуглей СК-1 и СК-2, приблизительно в 2 раза [5].

В ИК-спектрах сульфокатионитов на основе растительного сырья и ГМА присутствуют характеристические полосы поглощения валентных колебаний $\mathrm{C}-\mathrm{S}\left(582-612 \mathrm{~cm}^{-1}\right)$, симметричных валентных колебаний $\mathrm{S}=\mathrm{O}\left(1031-1035 \mathrm{~cm}^{-1}\right)$ и асимметричных валентных колебаний $\mathrm{S}=\mathrm{O}\left(1163 \mathrm{~cm}^{-1}\right)$ сульфогрупп. Отсутствие частот асимметричных валентных колебаний (810-950 $\left.\mathrm{cm}^{-1}\right)$ и симметричных валентных колебаний $\left(1250 \mathrm{~cm}^{-1}\right)$ эпоксидного кольца свидетельствует о его раскрытии с образованием ОН-групп, валентные колебания которых проявляются в ИК-спектрах в виде сильной широкой полосы поглощения при 3401-3420 $\mathrm{cm}^{-1}$. В них также отсутствует полоса поглощения при $1640 \mathrm{~cm}^{-1}$, соответствующая двойной $\mathrm{C}=\mathrm{C}$ связи ГМА, что указывает на полимеризацию ГМА. Наличие карбонильной группы подтверждается полосой поглощения при 1701-1704 см ${ }^{-1}$, имеющейся в спектрах синтезированных фитосорбентов.

Таблица 1. Оптимальные условия химического модифицирования сульфированных продуктов глицидилметакрилатом

\begin{tabular}{|c|c|c|c|c|c|c|}
\hline \multirow{2}{*}{ Катионит } & \multirow{2}{*}{$\begin{array}{c}\text { Соотношение сульфированного } \\
\text { продукта : ГМА, масс.ч. }\end{array}$} & \multicolumn{2}{|c|}{ Отверждение } & \multirow{2}{*}{$\begin{array}{l}\text { Выход, } \\
\%\end{array}$} & \multirow{2}{*}{$\mathrm{S}, \%$} & \multirow{2}{*}{$\begin{array}{l}\text { COE по } 0,1 \text { н раство- } \\
\text { py } \mathrm{NaOH}, \text { мг-экв } \cdot \Gamma^{-1}\end{array}$} \\
\hline & & $\mathrm{t},{ }^{\circ} \mathrm{C}$ & Время, ч & & & \\
\hline КС-ГМА-Х & $1,0: 8,0$ & 120 & 10 & 94,0 & 9,36 & 4,60 \\
\hline КС-ГМА-С & $1,0: 4,0$ & 120 & 8 & 96,0 & 8,32 & 5,85 \\
\hline КС-ГМА-К & $1,0: 2,0$ & 120 & 10 & 86,0 & 7,85 & 5,50 \\
\hline
\end{tabular}


Топологическая структура, задаваемая химическим строением и условиями синтеза, играет важную роль в формировании свойств ионитов. Как показывают микрофотографии (рис. 1, 2), морфология поверхностей пшеничной соломы, камыша и синтезированных из них серосодержащих катионитов значительно различается. Сравнение поверхностей сульфокатионитов показывает, что они отличаются размерами пор, которые увеличиваются в ряду: КС-ГМА-С $<$ КС-ГМА-К $<$ КС-ГМА-Х.

С помощью метода дериватографии проведена оценка термической устойчивости синтезированных фитосорбентов. В таблице 2 приведена потеря их массы при нагревании на воздухе в интервале температур $20-500{ }^{\circ} \mathrm{C}$ со скоростью нагрева $15^{\circ} \mathrm{C} \cdot$ мин $^{-1}$.

Как видно из таблицы 2, наибольшую термостабильность при нагревании на воздухе проявляет сульфокатионит на основе камыша, у которого потеря массы при $100{ }^{\circ} \mathrm{C}$ не превышает $10 \%$, а при температуре $300{ }^{\circ} \mathrm{C}$ она составляет $22 \%$.

Исследование их хемостойкости представляет практический интерес в связи с тем, что иониты часто используют в агрессивных средах. В таблице 3 приведены данные по изменению СОЕ фитосорбентов при кипячении в 5 н растворах $\mathrm{NaOH}$ и $\mathrm{H}_{2} \mathrm{SO}_{4}$ в течение 30 мин и при кипячении в воде в течение 50 ч.

a)

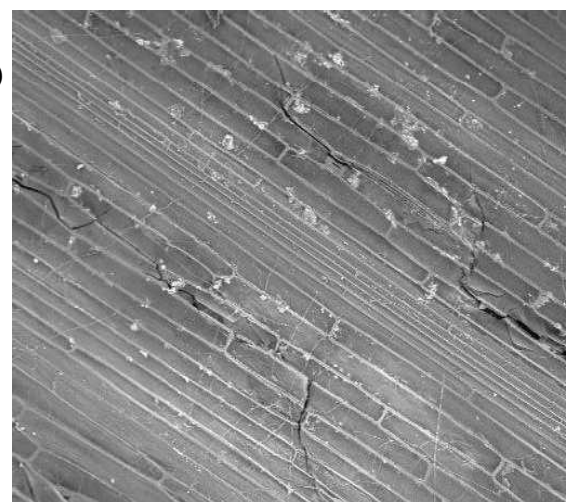

б)

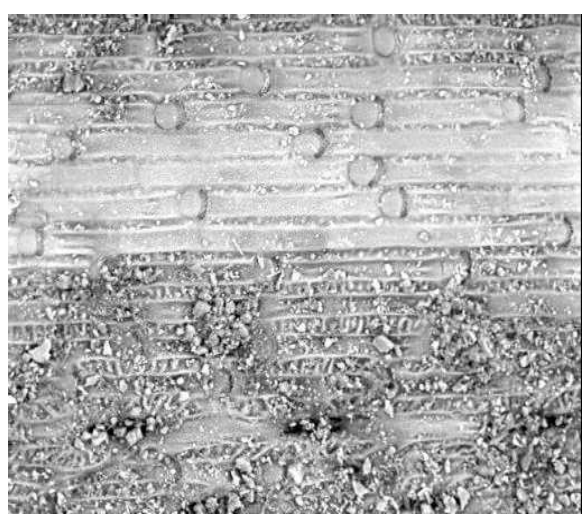

Рис. 1. Микрофотографии исходных пшеничной соломы (a) и камыша (б)

a)

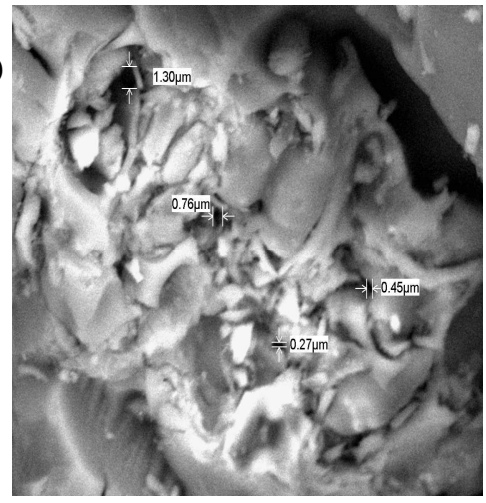

б)

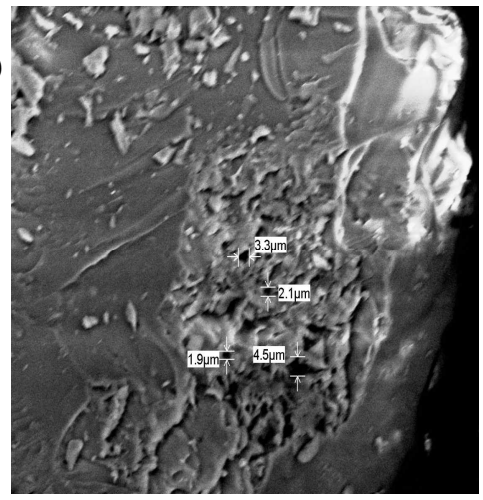

в)

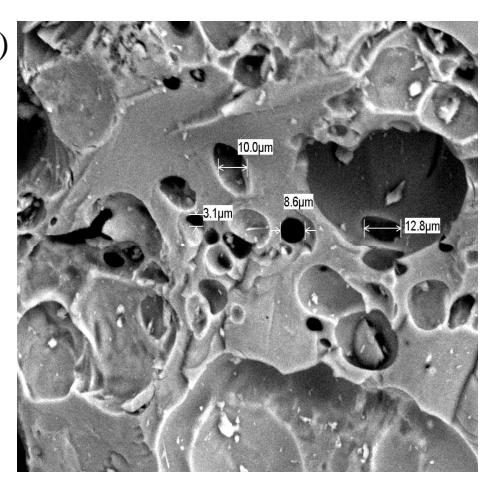

Рис. 2. Микрофотографии сульфокатионитов: КС-ГМА-С (a), КС-ГМА-К (б) и КС-ГМА-Х (в)

Таблица 3. Зависимость потери массы сульфокатионитов на основе растительного сырья и ГМА от температуры

\begin{tabular}{c|c|c|c|c|c}
\hline \multirow{2}{*}{ Катионит } & \multicolumn{5}{|c}{ Потеря массы, \% } \\
\cline { 2 - 6 } & $100{ }^{\circ} \mathrm{C}$ & $200{ }^{\circ} \mathrm{C}$ & $300{ }^{\circ} \mathrm{C}$ & $400{ }^{\circ} \mathrm{C}$ & $500{ }^{\circ} \mathrm{C}$ \\
\hline КС-ГМА-Х & 26 & 37 & 44 & 48 & 54 \\
КС-ГМА-С & 31 & 45 & 48 & 52 & 58 \\
КС-ГМА-К & 10 & 15 & 22 & 30 & 39 \\
\hline
\end{tabular}


Таблица 3. Хемо- и термостойкость сульфокатионитов на основе растительного сырья и ГМА

\begin{tabular}{|c|c|c|c|c|}
\hline \multirow{3}{*}{ Катионит } & \multirow{3}{*}{$\begin{array}{c}\text { Исходная СОЕ, } \\
\text { мг-экв· } \Gamma^{-1}\end{array}$} & \multicolumn{3}{|c|}{ СОЕ после обработки, мг-экв·Г ${ }^{1}$} \\
\hline & & \multicolumn{2}{|c|}{ Химическая устойчивость в растворах } & \multirow{2}{*}{$\begin{array}{l}\text { Термическая устой- } \\
\text { чивость в воде }\end{array}$} \\
\hline & & 5 н $\mathrm{NaOH}$ & $5 \mathrm{H} \mathrm{H}_{2} \mathrm{SO}_{4}$ & \\
\hline КС-ГМА-Х & 5,85 & 7,00 & 3,83 & 4,50 \\
\hline КС-ГМА-С & 5,20 & 5,50 & 2,83 & 5,00 \\
\hline КС-ГМА-К & 4,60 & 5,50 & 3,50 & 4,40 \\
\hline
\end{tabular}

Основной реакцией, приводящей к уменьшению обменной емкости сульфокатионитов при нагревании в воде, является десульфирование, которое сопровождается выделением в раствор эквивалентных количеств сульфат-ионов и ионов водорода [6]. Суммарную реакцию десульфирования катионитов в $\mathrm{H}^{+}$-форме можно записать в виде уравнения:

$$
\mathrm{RSO}_{3} \mathrm{H}+\mathrm{H}_{2} \mathrm{O}=\mathrm{RH}+\mathrm{H}_{2} \mathrm{SO}_{4} .
$$

Сульфокатиониты КС-ГМА-С и КС-ГМА-К проявляют высокую устойчивость к термическому гидролизу (табл. 3) и являются более перспективными для использования в водных средах при повышенных температурах, чем катионит на основе хлопка. Синтезированные фитосорбенты более устойчивы в щелочной среде, чем в кислой. Наибольшей химической стойкостью в растворе кислоты обладает сульфокатионит на основе камыша. Некоторое повышение значения емкости катионитов при обработке раствором щелочи можно объяснить вымыванием из полимерной сетки низкомолекулярных и растворимых продуктов реакции поликонденсации и увеличением доступности активных групп в фазе ионита.

На предприятиях цветной металлургии и металлоперерабатывающей промышленности в технологических процессах образуются сточные воды, загрязненные солями тяжелых металлов, которые оказывают весьма вредное влияние на экосистему [7]. В связи с этим исследование сорбционных свойств по отношению к ионам тяжелых металлов новых фитосорбентов представляет научный и практический интерес. Сорбционные свойства новых сульфокатионитов в сравнении с промышленным ионообменником КУ-2х8 по отношению к ионам тяжелых металлов приведены в таблице 4.

Как видно из таблицы 4 , при извлечении ионов тяжелых металлов из сульфатных растворов, содержащих 1,9-2,3 г·л ${ }^{-1}$ металлов ( $\mathrm{pH} 4,35-6,05$ ), сорбционная емкость (СЕ) всех фитосорбентов по ионам $\mathrm{Cu}^{2+}$ и $\mathrm{Pb}^{2+}$ ниже, чем у промышленного сульфокатионита КУ-2х8. Однако их сорбционная емкость по отношению к ионам $\mathrm{Cu}^{2+}\left(2,30-2,81\right.$ ммоль $\left.\cdot \Gamma^{-1}\right)$ гораздо выше, чем у сульфатной целлюлозы $\left(0,048\right.$ ммоль $\left.\cdot \Gamma^{-1}\right)[8]$. Катиониты КС-ГМА-С и КС-ГМА-К обладают более высокой извлекающей способностью по отношению к ионам $\mathrm{Co}^{2+}$, чем другие иониты. Более низкие сорбционные свойства сульфокатионита на основе хлопка обусловлены, по-видимому, его структурой. Из полученных результатов следует, что катионит на основе пшеничной соломы можно рекомендовать для извлечения ионов $\mathrm{Co}^{2+}$, а катионит, полученный из камыша, - для сорбции ионов $\mathrm{Co}^{2+}$ и $\mathrm{Zn}^{2+}$.

Из зависимостей СЕ сульфокатионитов от кислотности среды (рис. За) установлено, что ионит КУ-2×8 эффективно извлекает ионы $\mathrm{Co}^{2+}$ при 1,40-6,05, а сульфокатиониты на основе растительного сырья и ГМА - в более узком интервале $\mathrm{pH} 3,30-6,05$, при $\mathrm{pH} 0,35$ происходит снижение их извлекающей способности. Более полное извлечение ионов $\mathrm{Zn}^{2+}$ наблюдается при рН 5,2 (рис. 3б), что, очевидно, объясняется наибольшей степенью диссоциации ионогенных групп в таких растворах. При повышении кислотности ионизация функциональных групп снижается и сорбция ионов $\mathrm{Zn}^{2+}$ уменьшается, а на катионите КС-ГМА-С при рН 0,4-1,4 их поглощение полностью отсутствует.

Таблица 4. Сорбционные характеристики сульфокатионитов на основе растительного сырья и ГМА по отношению к ионам тяжелых металлов

\begin{tabular}{c|c|c|c|c|c}
\hline \multirow{2}{*}{ Катионит } & \multicolumn{5}{|c}{$\mathrm{CE}, \mathrm{M \Gamma} \cdot \Gamma^{-1}$} \\
\cline { 2 - 5 } & $\mathrm{Pb}^{2+}$ & $\mathrm{Co}^{2+}$ & $\mathrm{Zn}^{2+}$ & $\mathrm{Cu}^{2+}$ & $\mathrm{Ni}^{2+}$ \\
\hline КС-ГМА-С & 181,2 & 353,6 & 195,6 & 178,6 & 152,8 \\
КС-ГМА-К & 228,0 & 271,2 & 270,2 & 175,1 & 152,8 \\
КС-ГМА-Х & 207,2 & 200,4 & 176,4 & 146,0 & 105,6 \\
КУ-2х8 & 372,8 & 236,0 & 195,6 & 338,8 & 152,8 \\
\hline
\end{tabular}


a)

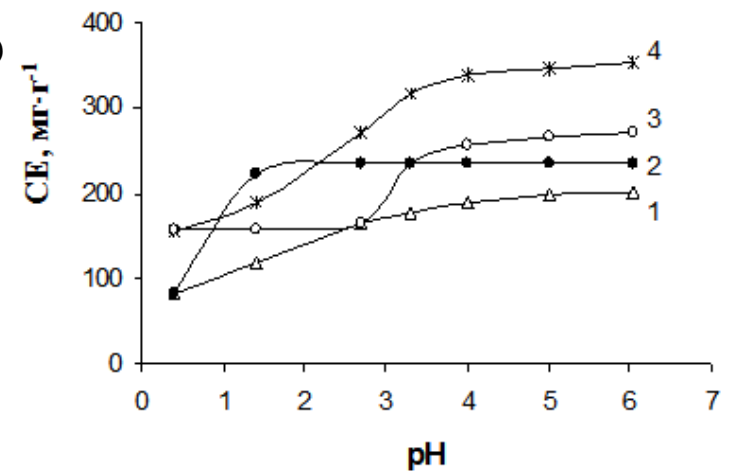

б)

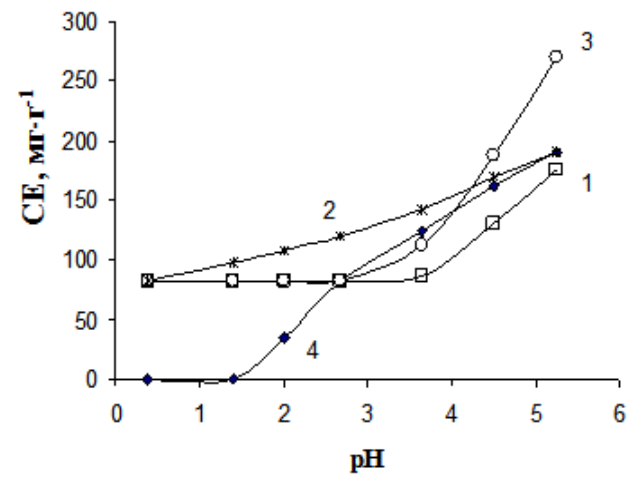

Рис. 3. Зависимость сорбции ионов $\mathrm{Co}^{2+}(a)$ и $\mathrm{Zn}^{2+}$ (б) сульфокатионитами КС-ГМА-Х (1), КУ-2х8 (2), КС-ГМА-К (3) и КС-ГМА-С (4) от кислотности среды (7 сут, $\mathrm{C}_{\mathrm{Co}}=2,3$ г $\cdot{ }^{-1}, \mathrm{C}_{\mathrm{Zn}}=2,0$ г.л $\left.{ }^{-1}\right)$

a)

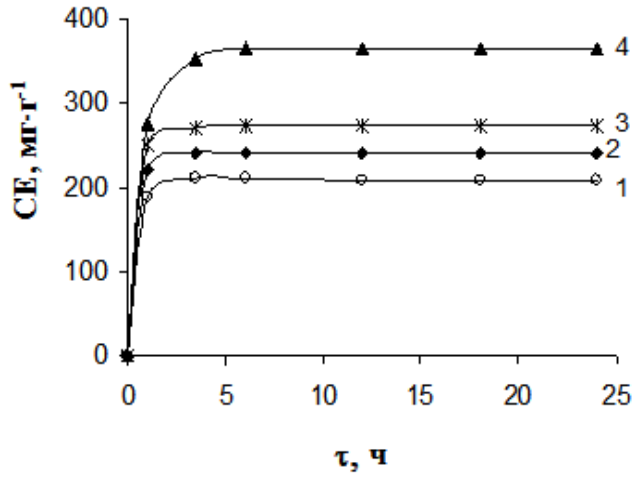

б)

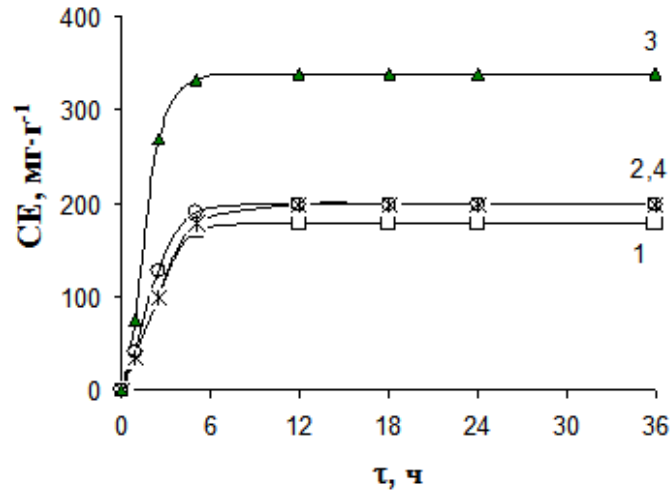

Рис. 4. Зависимость сорбции ионов $\mathrm{Co}^{2+}(a)$ и $\mathrm{Zn}^{2+}$ (б) сульфокатионитами КС-ГМА-Х (1), КУ-2х8 (2), КС-ГМА-К (3) и КС-ГМА-С (4) от продолжительности их контакта с раствором $\mathrm{CoSO}_{4}(\mathrm{pH}=6,05$, $\left.\mathrm{C}_{\mathrm{Co}}=2,45 \Gamma \cdot \mathrm{J}^{-1}\right)$

Из рисунка 4а видно, что все сульфокатиониты обладают высокими кинетическими свойствами, извлекая ионы $\mathrm{Co}^{2+}$ с довольно высокой скоростью в начальный период. Равновесное состояние между раствором $\mathrm{CoSO}_{4}$, содержащим 2,45 г.л ${ }^{-1}$ кобальта и имеющим $\mathrm{pH} 6,05$, и катионитами КУ-2х8 и КС-ГМА-Х устанавливается за 1 ч, а ионитами КС-ГМА-С и КС-ГМА-К - за 3 ч.

Для достижения равновесия на активированном углеродном волокне требуется более длительное время контакта $-1,5$ сут. [9]. При извлечении ионов $\mathrm{Zn}^{2+}$ фитосорбентами показано (рис. 4б), что равновесное состояние между раствором $\mathrm{ZnSO}_{4}$, содержащим 2,16 г·л ${ }^{-1}$ цинка, и катионитами достигается практически за 5 ч. При извлечении ионов $\mathrm{Cu}^{2+}$ и $\mathrm{Co}^{2+}$ из двухкомпонентных медь-, кобальтсодержащих сульфатных растворов установлено, что все сульфокатиониты, кроме катионита на основе камыша, не обладают селективностью к ним, поглощая одновременно оба катиона в широком интервале концентраций. Послед-

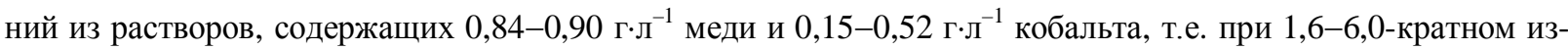
бытке меди избирательно сорбирует только ионы $\mathrm{Cu}^{2+}$. При других концентрациях ионов металлов в исходных растворах происходит коллективное поглощение $\mathrm{Cu}^{2+}$ и $\mathrm{Co}^{2+}$. Наибольшая суммарная обменная емкость по двум катионам наблюдается на сорбенте КС-ГМА-С и составляет 514,0 мГ. ${ }^{-1}$ из раствора, в которых содержание меди и кобальта составляет соответственно 0,95 и 2,36 г.л ${ }^{-1}$.

\section{Выводы}

Сульфированием хлопка, пшеничной соломы и камыша серной кислотой с последующим модифицированием глицидилметакрилатом получены новые серосодержащие катиониты.

Установлено, что сульфокатионит на основе пшеничной соломы обладает высокими сорбционными и кинетическими свойствами по отношению к ионам $\mathrm{Co}^{2+}$, а катионообменник, синтезированный из камыша, - к ионам $\mathrm{Co}^{2+}$ и $\mathrm{Zn}^{2+}$. 
Новый сульфокатионит на основе пшеничной соломы можно рекомендовать для группового извлечения ионов $\mathrm{Cu}^{2+}$ и $\mathrm{Co}^{2+}$ из промышленных растворов и сточных вод на предприятиях цветной металлургии.

\section{Список литературы}

1. Ергожин Е.Е., Бектенов Н.А., Акимбаева А.М. Полиэлектролиты на основе глицидилметакрилата и его сополимеров. Алматы, 2004. $271 \mathrm{c}$.

2. Ергожин Е.Е., Менлигазиев Е.Ж. Полифункциональные ионообменники. Алма-Ата, 1986. 304 с.

3. Убайдуллаев Б.Х., Кудратов А.М., Салимов 3.С. Подготовка и ионообменные свойства Р-содержащих производных целлюлозы из некоторых видов растений // Химия природных соединений. 2004. №4. С. 335-336.

4. Заботина А.П., Горяев М. И. Химический состав яровой пшеничной соломы // Гидролизная и лесохимическая промышленность. 1962. №4. С. 12-13.

5. Лурье А.А. Хроматографические материалы (справочник). М., 1978. 440 с.

6. Тулупов П.Е. Стойкость ионообменных материалов. М., 1984. 232 с.

7. Селицкий Г.А., Галкин Ю.А. Очистка сточных вод от ионов тяжелых металлов методом натрий-катионирования // Металлургия и машиностроение. 2008. №2. С. 5-7.

8. Никифорова Т.Е., Багровская Н.А., Козлов В.А., Лилин С.А. Сорбционные свойства и природа взаимодействия целлюлозосодержащих полимеров с ионами металлов // Химия растительного сырья. 2009. №1. С. 5-14.

9. Валинурова Э.Р., Кадырова А.Д., Шарафиева Л.Р., Кудашева Ф.Х. Использование активированных углеродных материалов для очистки сточных вод от ионов Ni (II), Co (II) и Сu (II) // Журнал прикладной химии. 2008. Т. 81. Вып. 11. С. 1822-1825.

Поступило в редакцию 5 мая 2011 г.

Ergozhin E.E., Nikitina A.I., Kabulova G.K. ${ }^{*}$, Bektenov N.A. SULFOCATIONITES ON THE BASIS OF VEGETABLE RAW MATERIAL AND GLYCIDYLMETHACRYLATE

Institute of Chemical Sciences. AB Bekturova, st. Sh.Ualikhanov, 106, Almaty, 050010 (Kazakhstan),

e-mail:kabgul@mail.ru

Possibility of receiving the sulfocationites on the basis of vegetable raw materials (cotton, wheat straw, bulrush) and glycidylmethacrylate is studied. Optimal conditions of synthesis are found and their physical and chemical properties are investigated. In static conditions sorption of ions of heavy metals $\mathrm{Cu}^{2+}, \mathrm{Zh}^{2+}, \mathrm{Ni}^{2+}, \mathrm{Co}^{2+}$ and $\mathrm{Pb}^{2+}$ with new cellulose containing sorbents from the model sulphate solutions in comparison with industrial sulfocationite KУ-2x8 is studied.

Keywords: vegetable raw materials, glycidylmethacrylate, sulfocationites, sorption properties, ions of heavy metals.

\section{References}

1. Ergozhin E.E., Bektenov N.A., Akimbaeva A.M. Polielektrolity na osnove glitsidilmetakrilata i ego sopolimerov. [Polyelectrolytes based on glycidyl methacrylate and copolymers thereof]. Almaty, 2004, 271 p. (in Russ.).

2. Ergozhin E.E., Menligaziev E.Zh. Polifunktsional'nye ionoobmenniki. [Polyfunctional ion exchangers]. Almaty, 1986, 304 p. (in Russ.).

3. Ubaidullaev B.Kh., Kudratov A.M., Salimov Z.S. Khimiia prirodnykh soedinenii, 2004, no. 4, pp. 335-336. (in Russ.).

4. Zabotina A.P., Goriaev M.I. Gidroliznaia i lesokhimicheskaia promyshlennost', 1962, no. 4, pp.12-13. (in Russ.).

5. Lur'e A.A. Khromatograficheskie materialy (spravochnik). [Chromatographic materials (Handbook).]. Moscow., 1978, 440 p. (in Russ.).

6. Tulupov P.E. Stoikost' ionoobmennykh materialov. [Persistence of ion exchange materials]. Moscow, 1984,232 p. (in Russ.).

7. Selitskii G.A., Galkin Iu.A. Metallurgiia i mashinostroenie, 2008, no. 2, pp. 5-7. (in Russ.).

8. Nikiforova T.E., Bagrovskaia N.A., Kozlov V.A., Lilin S.A. Khimiia rastitel'nogo syr'ia, 2009, no. 1, pp. 5-14. (in Russ.).

9. Valinurova E.R., Kadyrova A.D., Sharafieva L.R., Kudasheva F.Kh. Zhurnal prikladnoi khimii, 2008, vol. 81, no. 11, pp. 1822-1825.

\footnotetext{
* Corresponding author.
} 